\title{
Measures to Develop Advanced Mathematics Curriculum Ideology and Politics
}

\author{
Cunrong Wang*, Haijing Zhu, Ying Li \\ School of Mathematics and Statistics, Qilu University of Technology (Shandong Academy of \\ Sciences), Jinan 250353, China \\ *Corresponding author: Cunrong Wang, 1191984686@qq.com
}

Keywords: Advanced mathematics, Curriculum ideology and politics, Ideological and political elements

\begin{abstract}
In order to develop advanced mathematics curriculum ideology and politics, teachers of advanced mathematics should strive to be more conscious of their curriculum ideology and politics and improve their ability to teach it. In the teaching process, teachers should guide students to establish critical spirit and rational spirit by exerting the educational function of advanced mathematics knowledge system. Teachers of advanced mathematics must lead students to respect the scientific spirit through the application of calculus development history. Teachers of advanced mathematics carry out national conditions education for students through organic integration into relevant societal issues. School leaders should attach great importance to advanced mathematics curriculum ideology and politics and strengthen the support and guidance of curriculum ideology and politics from the system and mechanism. The leaders of university should emphasize advanced mathematics curriculum ideology and politics. The leaders of university should give more support and guidance to advanced mathematics curriculum ideology and politics from the system and mechanism.
\end{abstract}

\section{Introduction}

In December 2016, General Secretary Xi Jinping stated at the National Conference on Ideological and Political Work in Colleges and Universities that ideological and political theory courses should be strengthened, and other courses should keep a good section of canal and plant responsible fields, so that all kinds of courses, especially ideological and political theory courses, can work in the same direction and form synergies [1].

In recent years, curriculum ideology and politics has gained relevance among experts and scholars. The current research on curriculum ideology and politics mainly focuses on four aspects: the connotation and value of curriculum ideology and politics are explained from the perspective of epistemology; the achievements and experiences of construction of curriculum ideology and politics in universities are summarized from the perspective of methodology and practicalism; several pairs of relations should be emphasized from the perspective of contradiction; and the macro system construction and system construction of curriculum ideology and politics are discussed from the perspective of systematology. The researchers are primarily teachers of ideological and political 
theory in the School of Marxism [2]. From the perspective of the research subject, there remains a disconnect between the educational idea of curriculum ideology and politics and its teaching practice, and there is little research on the theory and practice of advanced mathematics curriculum ideology and politics.

Advanced mathematics is a compulsory basic theory course for non-mathematics majors in science and engineering colleges. The theory and politics of higher mathematics curriculum is an important platform to realize the three-dimensional goals of knowledge and ability, process and method, emotion and attitude and values. Therefore, it is of great significance to study the development of advanced mathematics curriculum ideology and politics.

\section{Connotation of Advanced Mathematics Curriculum Ideology and Politics}

There are many scholarly connotations of curriculum ideology and politics, including curriculum type theory, educational concept theory, ideological and political method theory, teaching system theory, practical activities theory, multiple attributes theory, and so on [3]. Different theories reveal a certain aspect of curriculum ideology and politics from their respective angles. However, the "curriculum type theory" that regards curriculum ideology and politics as a kind of curriculum is an incorrect understanding of curriculum ideology and politics [4]. Curriculum type theory not only affects all kinds of courses and ideological and political theory courses in the same direction, but also affects their synergies. Curriculum ideology and politics is essentially a kind of curriculum view, which is not to add a course or an activity, but to integrate the ideological and political education in universities into every link and aspect of curriculum teaching and reform. The purpose of curriculum ideology and politics is to achieve moral education and cultivate people in moistening things silently [5].

The essence of advanced mathematics curriculum ideology and politics is the teaching objectives of knowledge imparting, ability cultivation, and value shaping in the curriculum standards. Teachers of advanced mathematics choose effective teaching methods and organically integrate ideological and political elements into the teaching process of advanced mathematics. Advanced mathematics curriculum ideology and politics is the teaching idea and method to train the socialist builders and successors with all-round development of morality, intelligence, physique, aesthetics and labor. The so-called organic integration requires that the elements of advanced mathematics curriculum ideology and politics explored by teachers are not mechanically copied, but must be contained in the curriculum itself. On this basis, teachers optimize content according to the teaching needs [6].

\section{Measures to Develop Advanced Mathematics Curriculum Ideology and Politics}

The measures to develop advanced mathematics curriculum ideology and politics are multi-level, multi-way, and multifaceted. This article mainly discusses the following aspects.

\subsection{Improving the Curriculum Ideology and Politics Ability of Advanced Mathematics Teachers}

The teachers of higher mathematics should strengthen the consciousness of ideological and political education, enrich the knowledge of ideological and political education, and improve the consciousness and ability of curriculum ideology and politics.

(1) Strengthening the consciousness of curriculum ideology and politics in the study and dissemination of ideological and political education theory

Teachers are the primary resource for the development of education and an important cornerstone for the prosperity of the country, the rejuvenation of the nation, and the happiness of the people [7]. 
Marx pointed out that "the environment is changed by people, and the educator himself must be educated" [8]. General Secretary Xi Jinping stressed that "teachers are engineers of the human soul and shoulder a sacred mission. The preacher himself must first understand and believe the Word" [9]. College teachers should firmly establish the "four consciousness", always firm "four confidence", and firmly achieve "two maintenance".

(2) Improving the ability of curriculum ideology and politics in practice and research of curriculum ideology and politics

Advanced mathematics teachers generally possess profound professional knowledge. However, advanced mathematics teachers "should not only be the 'teacher' who imparts book knowledge, but the 'big man' who shapes students' character, conduct and taste” [10]. First, curriculum ideology and politics needs teachers to reflect in teaching practice, practice in reflection, so that teachers can not only identify their own shortcomings and deficiencies, but also prompt teachers to quickly and effectively make up for deficiencies. For example, teachers should reflect on whether they lack theoretical knowledge of ideological and political education, whether the elements of curriculum ideology and politics are organically integrated into teaching, and whether the evaluation standard of curriculum ideology and politics is reasonable. Second, curriculum ideology and politics requires teachers to conduct action research on both "goodness" and "truth" [11]. The action research on advanced mathematics curriculum ideology and politics not only appeals to the "goodness" of students' mathematical thinking, humanistic quality, and values, but also appeals to the "truth" of analyzing and summarizing action research results and constructing them as theoretical research results. Only in this way, teachers of advanced mathematics can improve their ability of curriculum ideology and politics in practice and research.

\subsection{Integrating the Elements of Advanced Mathematics Curriculum Ideology and Politics into the Teaching Process}

(1) Bringing into play the educational function of the advanced mathematics knowledge system to guide the students to establish the critical spirit and rational spirit

First, the "objectivity" and "universality” of advanced mathematical knowledge denote that it does not change even with changes in ideology, values, lifestyle, gender, or race [12]. In this sense, the language of mathematics is universal. For example, the concept of function derivatives and the rules for finding derivatives of functions are the same in calculus textbooks in any country. Second, the teaching of higher mathematics should not only concern the small skills of 'calculation' but also focus on the deduction, analysis and identification, comprehensive generalization, and comparative demonstration of knowledge. In the logical process of displaying knowledge, advanced mathematics should enable students to form their own understanding, judgment, and creativity through the construction of knowledge; pursue truth; experience rational and rigorous thinking; and refine their ability and accomplishment. The unique intrinsic value in advanced mathematics courses has been realized [13]. Third, teachers should guide students to develop a "cautious optimism." Students should have confidence in their ability to learn. Students should not only make bold guesses, but also make arguments with an optimistic attitude. However, students should not believe anything easily and should feel empowered to revise any of their beliefs at any time [14]. In this way, students' critical spirit and rational spirit can be cultivated.

(2) Making use of the development history of calculus to guide students to respect the scientific spirit

Calculus was born in the 17th century, perfected in the 19th century, and opened a new era in the history of mathematics. Engels once commented on calculus thusly: "There is not necessarily anything else as the invention of calculus in the second half of the 17th century as the highest victory 
of the human spirit among all theoretical achievements."

However, calculus was criticized for its imperfect theoretical foundation at the beginning of its establishment. Theologian George Berkeley (1685-1753) criticized a series of important concepts in calculus, such as infinitesimal increments and instantaneous velocity, as "obscure mysteries," "vague confusion," and "unreasonable absurdity." His powerful criticism of calculus not only produced the most shocking impact in mathematics, but also led to the second crisis in the history of math. The second mathematical crisis at once showed the extensive influence of calculus from one side and reflected the pioneering spirit of the predecessors who studied calculus from another side.

Almost every mathematician made unremitting efforts to solve the second mathematical crisis of the 18th century. For example, Augustin-Louis Cauchy (1789-1857) gave a descriptive definition of limits. He also defined "infinitesimal" as a variable with a limit of zero [15]. Karl Weierstrass (18151897) gave the $\varepsilon-N \quad(\varepsilon-\delta)$ definition of a limit in order to eliminate the uncertainty caused by the previous descriptive definition. David Hilbert (1862-1943) praised Weierstrass for establishing a solid foundation for mathematical analysis with his critical spirit and deep insight [16]. With the joint efforts of many mathematicians, the second mathematical crisis was declared to be completely solved more than 200 years after the reconstruction of calculus. It was a triumphant day for mathematicians. The tortuous and inspiring history of calculus will lead students to respect the spirit of scientists.

(3) Integrating into contemporary societal issues to educate students about the state of the country and the world

Throughout the teaching process of higher mathematics, teachers organically integrate their curriculum into the real world to motivate students to care about family affairs, national affairs, and world affairs. For example, the teacher introduces the meaning of carbon peak and carbon neutral when students learn the extreme and maximum values of functions. Climate change poses a severe challenge to human survival and development. The phrases 'carbon peak' and 'carbon neutral' were proposed at the Central Economic Work Conference held in Beijing in December 2020. China has announced that it aims to achieve carbon peak by 2030 and carbon neutral by 2060. The goal is a major strategic decision made to build a community with a shared future for mankind and achieve sustainable development. China needs to work hard to achieve the goal. The teacher should ask questions that arouse students' reflection. For example, what steps can individuals take regarding food, clothing, shelter, and transportation to achieve the goal? Through careful analysis, students can develop good habits of green travel, low-carbon life, energy saving, and emission reduction in their studies and life. Students can contribute their wisdom and strength to the goal of carbon peak and carbon neutral.

\subsection{Giving More Support and Guidance to Advanced Mathematics Curriculum Ideology and Politics by School Leaders}

(1) Establishing a linkage mechanism between advanced mathematics curriculum and ideological and political curriculum

Under the leadership of the University Party Committee, the School of Marxism coordinates and cooperates with the school of developing curriculum ideology and politics to break down disciplinary barriers and institutional barriers between curriculums. Resources from different disciplines and teachers are integrated together [17]. Schools can give priority to the construction of backbone teachers team, select a group of backbone teachers to form a "curriculum ideology and politics community," and create several "curriculum ideology and politics" demonstration curriculums.

(2) Establishing an effective evaluation system

Reasonable evaluation can mobilize teachers' potential and improve their enthusiasm and creativity [18]. School leaders should alter the evaluation concept and break away from the traditional, 
single-student evaluation system. Teachers, students, and administrators of curriculum ideology and politics construction are the most qualified evaluation subjects. Student evaluation focuses on the "learning" of educational knowledge; peer evaluation focuses on the "teaching" of educational skills; and manager evaluation focuses on the "action" of value-led [19]. School leaders should formulate evaluation criteria for curriculum ideology and politics construction and development. All kinds of evaluation criteria support and complement each other, and eventually form perfect evaluation criteria to achieve the purpose of promoting teaching through evaluation.

\section{Conclusions}

Advanced mathematics teachers should learn and improve their own ability to teach curriculum ideology and politics. They should exert the educational function of the knowledge system of higher mathematics to guide students to establish critical spirit and rational spirit, use the history of calculus to guide students to respect the spirit of scientists, and organically integrate curriculum into the real world to carry out the education of national conditions and world conditions for students. Additionally, school leaders should give more support and guidance to curriculum ideology and politics.

However, there are still many roadblocks in the development of advanced mathematics curriculum ideology and politics. For example, the elements of curriculum ideology and politics are not rich enough. The way to integrate the elements of curriculum ideology and politics into the course is stiff. These are questions that need further study.

\section{Acknowledgement}

This research was supported by Qilu University of Technology (Shandong Academy of Sciences) Teaching Research Project (2020szzx23) and the Second Batch of New Engineering Research and Practice Specialty Reform Project (E-RCZN20201029).

\section{References}

[1] National College Ideological and Political Work Conference held in Beijing on December 7-8, 2016 [EB/OL]. http://www.gov.cn/xinwen/2016-12/08/Content_5145253.htm\#allcontent.

[2] He W, Wang L. Review and Prospect of Curriculum Ideological and Political Research in China [J]. School Party Building and Ideological Education, 2021(04):26-30.

[3] Tang D, Li X, Guo X. Three Questions of Curriculum Ideology and Politics: Essence, Boundary and Practice [J]. Modern Education Management, 2020(10):52-58.

[4] He Y. Exploration on the Essential Connotation and Realization Path of "Curriculum Ideology and Politics" [J]. Ideological and Theoretical Education Guide, 2019, (10):130-134.

[5] Gao D, Zong A. Curriculum Ideology and Politics: an Inevitable Choice to Effectively Play the Role of the Main Channel of Classroom Education [J]. Ideological and Theoretical Education Guide, 2017, (1):31-34.

[6] Zhang Ch. Teachers' Consciousness of Curriculum Ideology and Politics Construction and its Cultivation [J]. Ideological and Theoretical Education, 2020(9): 71-76.

[7] Opinions of the CPC Central Committee and The State Council on Comprehensively Deepening the reform of teacher team construction in the New Era [EB/OL].http://www.gov.cn/zhengce/2018-01/31/content_5162659.htm.

[8] Collected Works of Marx and Engels: Volume 1 [M]. Beijing: People's Publishing House, 2009:504.

[9] Xi J. Ideological and Political Work Throughout the Whole Process of Education and Teaching, Creating a New Situation for the Development of Higher Education in China [N]. People's Daily, 2016-12-09 (01).

[10] Becoming the students" "Mr. Big" [EB/OL]. https://www.chinanews.com/gn/2018/09-08/8622025.shtml.

[11] Wang C. Review of “Action Research” [J]. Contemporary Education Science, 2010, (5):10-11.

[12] Shi Z. Knowledge Transformation and Education Reform [M]. Beijing: Education Science Press, 2002:137.

[13] Gao G. The Improvement of Teachers' Ideological and Political Consciousness and Ability in Curriculum [J]. Educational research, 2020,41(09):23-28.

[14] Zheng Y. Introduction to Mathematical Methodology [M]. Hangzhou: Zhejiang Education Press, 2006:54.

[15] Katz, V. J. General Theory of Mathematical History [M]. Beijing: Higher Education Press, 2004:551. 
[16] Han X. Mathematical Paradox and Three Mathematical Crises [M]. Changsha: Hunan Science and Technology Press, 2006:200.

[17] Qiu R. Theoretical Interpretation of “Curriculum Ideology and Politics” and "Ideological and Political Curriculum” in the Same Direction [J]. Ideological Education Research, 2018, (4):109-113.

[18] Wang Y, Guo C. Pedagogy [M]. Beijing: Beijing Normal University Press, 2012:310.

[19] Zhang Ch. Teachers' Awareness of Curriculum Ideology and Politics Construction and its Cultivation [J]. Ideological and Theoretical Education, 2020(9):71-76. 